\title{
Prevalence and factors associated with anterior open bite in 2 to 5 year old children in Benin city, Nigeria
}

\author{
*Ize-Iyamu I N ${ }^{1}$, Isiekwe M C ${ }^{2}$
}

1. Departments of Preventive Dentistry, University of Benin Teaching Hospital, Nigeria

2. Department of Child Dental Health, College of Medicine, University of Lagos, Nigeria

\begin{abstract}
Background: Anterior open bite is said to exist when there is an actual vertical gap between the upper and lower incisors with the teeth in centric occlusion. This could occur in the anterior or posterior region, and may be attributed to the supra eruption of the posterior teeth or the infra eruption of the anterior teeth and it is common in both adults and children.

Objective: To evaluate the prevalence of anterior open bite (AOB) in 2 to 5 -year-old children and the aetiological factors responsible for it.

Methods: The study group comprised 1031 children (429 boys and 602 girls) between the ages of 2 to 5 -years, who were examined for the presence of $\mathrm{AOB}$ and the relationship with various oral habits.

Results: AOB was present in $29(2.8 \%)$ of the subjects. Sucking habits were observed in $267(25.9 \%)$ children. Only 29 $(10.9 \%)$ of the children with sucking habits had an AOB which was asymmetric in $20(7.5 \%)$ and symmetric in $9(3.4 \%)$. The asymmetric AOB was significantly higher in children with thumb sucking habits than in finger suckers $(\mathrm{P}<0.05)$. There was no significant difference between frequency, duration of sucking habits and AOB. The 4-year olds showed a significant difference in the number of children with AOB $(\mathrm{P}<0.05)$. Sucking habits of 1-2 hours and duration of 24 to 60 months exhibited the highest prevalence of an $\mathrm{AOB}$ in $13(44.8 \%)$ and 17 (58.6\%)children respectively.

Conclusion: The prevalence of AOB in this study is $2.8 \%$. Thumb sucking is the most important aetiological factor in the formation of an AOB in 2 to 5-year-old children.

African Health Sciences 2012; (4): 446 - 451 http://dx.doi.org/10.4314/ahs.v12i4.8
\end{abstract}

\section{Introduction}

Anterior open bite is said to exist when there is an actual vertical gap between the upper and lower incisors with the teeth in centric occlusion ${ }^{1}$. Anterior open bite as defined by Subtelny and Sakuda ${ }^{2},{ }^{3}$ is the deviation in the vertical relationship of the maxillary and mandibular dental arches with a definite lack of contact in the vertical direction between opposing segments of teeth. It was also defined by McSherry as a vertical occlusal anomaly with no vertical overlap of the upper and lower incisors ${ }^{4}$. Anterior open bite is also described as a condition in which the upper incisor teeth crowns fail to overlap the incisal third of the lower incisor crowns when the mandible is brought into full occlusion. This was also described as a vertical discrepancy ${ }^{1,5}$. Also, it is said to exist when there is no incisor contact and vertical overlap of the lower incisors by the upper and are characterized by failure of the teeth in both arches to meet properly ${ }^{5}$. Another term used in describing

\footnotetext{
*Corresponding author:

Dr Idia N Ize- Iyamu

P. O. Box 7022

Benin City, Edo State

Nigeria

E-mail: idiaize@yahoo.com
}

anterior open bite is apertognathia and could be said to be failure of the anterior teeth to make contact when the jaw is firmly closed ${ }^{6}$. This could occur in the anterior or posterior region, and may be attributed to the supra eruption of the posterior teeth or the infra eruption of the anterior teeth and it is common in both adults and children.

Definitions on the aetiology and prevalence of anterior open bite vary and a review of the literature shows various aetiological classifications ${ }^{5}$, 7-11 which could also be pathologic, neurologic or iatrogenic ${ }^{8-11}$. Others include a clinical classification in which the open bite could be dental ${ }^{3-9}$, asymmetrical if it affects only one segment, or symmetrical if it affects both segments of the jaws and is seen in the majority of children in the transitional and mixed dentition stage $1,3,4,8,9$

Prevalence rates for anterior open bite have ranged from 2 to 8 percent from other studies in pre-school children ${ }^{10,13,14}$ and from 1.5 to 16.5 percent in older children ${ }^{1,15-19}$. Few studies on the prevalence of anterior open bite in pre-school children have however been carried out in our environment. Previous Nigerian studies ${ }^{12,20-22}$ revealed a prevalence of oral habits of $13.14 \%{ }^{15}$ and a 
prevalence of an anterior open bite of $2.1 \%{ }^{13}$ and $4.1 \%{ }^{23}$ in school children aged 11-16-years of age. Few studies have however been carried out on the prevalence of anterior open in pre-school children in our environment.

The implication of an anterior open bite irrespective of the aetiological cause include aesthetic concerns, speech disorders, lingual interposition during swallowing and difficulty in biting with the incisor teeth ${ }^{1-5,23-24}$. Patients with an anterior open bite may present with deficient labial contact, mouth breathing frequently characterized by an open mouth posture ${ }^{5}$, they may or may not exhibit retroclined incisors, a narrow " $v$ " shaped palatal vault ${ }^{5-8}$ and atypical phonation affecting the production of the following phonetic sounds: /t/, /d/, /n/, /l/, /r/ .${ }^{24}$. Anterior open bites can be prevented if the aetiological factors are identified early and some form of intervention carried out ${ }^{2,3,6-8}$. These may include behavioral therapy, and appliances ${ }^{1,912,23}$. The early treatment of an anterior open bite in the primary dentition will provide better aesthetic and functional outcomes but the most common aetiologic factors must be considered before treatment.

Habits have been associated as one of the most common aetiological agents in the occurrence of anterior open bites, with the thumb, digit and tongue being most frequently sucked $2-5,7,8,10-13,23$. Habits are numerous and varied and include thumb and finger sucking, dummy sucking, pacifier sucking, tongue thrusting and lip sucking ${ }^{1,3-5,9-12,20}$. Anterior open bite is more common and clearly dominant in 3 -year-old children who persist in a sucking habit ${ }^{24}$ Prolonged thumb and finger sucking often leads to an anterior open bite and a disturbance of the dentofacial development in the anteroposterior, vertical and transverse directions with the largest impact on the position of the front teeth ${ }^{23-25 .}$ Other habits like finger or digit sucking have been implicated in the aetiology of an anterior open bite ${ }^{12,20,22}$, however finger sucking was more predominant in the formation of anterior open bite $20,23,26-27$.

The purpose of this study was to determine the prevalence of anterior open bite in 2-5-year-old children and identify the most common aetiological factors.

\section{Methods}

This cross sectional study was developed in two stages and two sampling methods were used: the stratified random sampling in which the children were stratified according to age, and the cluster sampling which was used in day care centres.

Informed consent was obtained from both the school authorities and parents or guardians of 1200 children between the ages of 2 to 5 -years chosen randomly from pre-school or day care centres. A list of pre-schools and day-care centres was obtained from the State Ministry of Education and every ' $n$ 'th school selected ( $\mathrm{n}$ was a number taken from a statistical table). In each selected pre-school, children for the study were selected from the class register using simple random sampling. For the day care centres, cluster sampling was used.

Sample size was determined by using the highest prevalence rate of $33.3 \%$ from a similar comparative study on malocclusion in Nigeria ${ }^{28}$ and a formula for a prevalence study ${ }^{29}\left(\mathrm{n}=(1.96)^{2} \mathrm{P}(100-\right.$ p) $/ d^{2}$ ) applied with a confidence level pre-set at $95 \%$. This gave a minimum sample size of 948 children for a $1 \%$ margin of error. However, a final sample size of 1031 children out of 1200 questionnaires distributed was obtained giving a response rate of $86 \%$. The questionnaires including the oral examinations were pre-tested in a pilot study in the largest local government area on 50 children under similar conditions to that used in this study. The data obtained was however not included in the final analysis. The intra-examiner reproducibility was assessed by re-examination of sixty randomly selected school children two weeks after their initial selection. The kappa score was 0.80 indicating a good agreement.

Inclusion criteria included children who had all their primary teeth present in the mouth. Those with evidence of mobility, caries, loss of anterior teeth due to trauma, extraction or physiological loss and attrition were excluded from the study.

Epi info version 6 (The Epi Info computer programs are produced by CDC and the World Health Organization) was used to construct a structured questionnaire and code the response and the following data which included the age to the nearest birthday, socio-demographic data, frequency and duration of habits was recorded by parents or guardians of all children included in the study.

An intra oral examination was carried out by one investigator (INI) to determine the presence of anterior open bite which was then measured with a pair of self locking dividers and transferred onto a ruler. Where an open bite existed, a second measurement was taken at the completion of examination of the class. This was to reduce the effect 
of memory bias. Statistical Package for the Social Sciences-Chicago (SPSS) version 15 was used to analyse the data and chi square and t-test applied where appropriate with $\mathrm{P}$ values $(\mathrm{p}<0.05)$ regarded as significant.

\section{Results}

The study population consisted of 1031 pre-school children and comprised of $602(58.3 \%)$ girls and $429(41.7 \%)$ boys aged 2-5-years. The prevalence of anterior open bite in the community was $2.8 \%$ (table 1). Sucking habits were present in 267 (25.9\%) children. Thumb sucking had the highest frequency of $88(33 \%)$ while pacifier sucking was not common and was seen in only $12(4.5 \%)$ table 2 .

Table 1: Gender distribution of children with sucking habits and anterior open bite

\begin{tabular}{lcccc}
\hline Gender & Sucking habits & \multicolumn{2}{c}{$\begin{array}{c}\text { Anterior open bite } \\
\text { present }\end{array}$} & Total \\
& & $\mathbf{n} \%$ & $\mathbf{n} \%$ & \\
\hline Boy & $133(49.8)$ & $14(48.3)$ & $415(41.4)$ & $429(41.7)$ \\
Girls & $134(50.2)$ & $15(51.7)$ & $587(58.9)$ & $602(58.3)$ \\
Total & $267(25.9)$ & $29(2.8)$ & $1002(97.2)$ & $1031(100)$ \\
\hline Chi square $=0.60$ & \multicolumn{2}{l}{ P value $>0.05$} & Degree of freedom $=1$
\end{tabular}

Table 2: Percentage prevalence of various oral habits

\begin{tabular}{lll}
\hline Habit & Number & $\mathbf{\%}$ \\
\hline Thumb sucking & 88 & 33 \\
Finger sucking & 71 & 26.6 \\
Tongue sucking & 46 & 17.2 \\
Pacifier sucking & 12 & 4.5 \\
Lip and cheek & 50 & 18.7 \\
\hline
\end{tabular}

Anterior open bite was present in $29(10.9 \%)$ of children with sucking habits. Thumb suckers showed the highest prevalence of open bite in 17(19.3\%), followed by the finger suckers with a prevalence of $9(12.7 \%)$ and pacifier suckers exhibiting no open bite. The asymmetric open bite was present in 20 (7.5\%) while $9(3.4 \%)$ exhibited a symmetric open bite.
There was a statistically significantly higher prevalence of asymmetric anterior open bite in children with sucking habits than those without $(\mathrm{p}<0.05$.) table 3 . The 4-year olds showed a statistically significant difference in the number of children with anterior open bite $(\mathrm{p}<0.05)$ table 4.

Table 3: Prevalence of anterior open in various oral habits

\begin{tabular}{|c|c|c|c|c|c|}
\hline \multicolumn{6}{|c|}{ Anterior open bite } \\
\hline \multirow{2}{*}{$\begin{array}{l}\text { Sucking } \\
\text { Habits }\end{array}$} & \multicolumn{2}{|c|}{ Present } & \multirow[b]{2}{*}{$\begin{array}{l}\text { Total } \\
\mathrm{n} \%\end{array}$} & \multirow{2}{*}{$\begin{array}{l}\text { Absent } \\
\mathrm{n} \%\end{array}$} & \multirow{2}{*}{$\begin{array}{l}\text { Total } \\
\mathrm{n} \%\end{array}$} \\
\hline & $\begin{array}{l}\text { Asymmetric } \\
\text { n \% }\end{array}$ & $\begin{array}{c}\text { Symmetric } \\
\mathrm{n} \%\end{array}$ & & & \\
\hline Thumb & $14(15.9)$ & $3(3.4)$ & $17(19.3)$ & $71(80.7)$ & $88(100)$ \\
\hline Finger & $4(5.7)$ & $5(7)$ & $9(12.7)$ & $62(87.3)$ & $71(100)$ \\
\hline Tongue & $1(2.2)$ & $1(2.2)$ & $2(4.4)$ & 44 (21.4) & $46(100)$ \\
\hline Pacifier & - & - & - & $12(100)$ & $12(100)$ \\
\hline $\begin{array}{l}\text { Lip and } \\
\text { cheek }\end{array}$ & $1(2)$ & - & 1(2) & $49(98)$ & $50(100)$ \\
\hline Total & $20(7.5)$ & $9(3.4)$ & $29(10.9)$ & $238(89.1)$ & $267(100)$ \\
\hline
\end{tabular}

Chi square $=001 \quad P$ value $<0.05$

Degree of freedom $=1$ 
Table 4: Distribution of anterior open bite among age groups

\begin{tabular}{lcccc}
\hline \multirow{2}{*}{ Age (in years) } & \multicolumn{3}{c}{ Anterior open bite } & \multirow{2}{*}{$\begin{array}{c}\text { Total } \\
\mathbf{n} \%\end{array}$} \\
\cline { 2 - 4 } & $\begin{array}{l}\text { Present } \\
\mathbf{n} \%\end{array}$ & chi square $\begin{array}{c}\text { Absent } \\
\mathbf{n} \%\end{array}$ & \\
\hline 2 & $2(6.9)$ & 0.86 & $152(15.1)$ & $154(14.9)$ \\
3 & $4(13.8)$ & 0.40 & $292(29.2)$ & $296(28.7)$ \\
4 & $12(41.4)$ & $0.02^{*}$ & $295(29.5)$ & $307(29.9)$ \\
5 & $11(37.9)$ & 0.98 & $263(26.2)$ & $274(26.5)$ \\
Total & $29(100)$ & & $1002(100)$ & $1031(100)$ \\
\hline
\end{tabular}

$\mathrm{P}=0.02^{*}$ (statistically significant)

Figure 1 shows no significant difference between the frequency of the various habits and anterior open bite, but those children who sucked between 1-3 hours a day exhibited the highest frequency with 13 $(44.8 \%)$. Those children who sucked for duration of 24-60 months exhibited the highest frequency of anterior open bite with 17 (58.6\%).

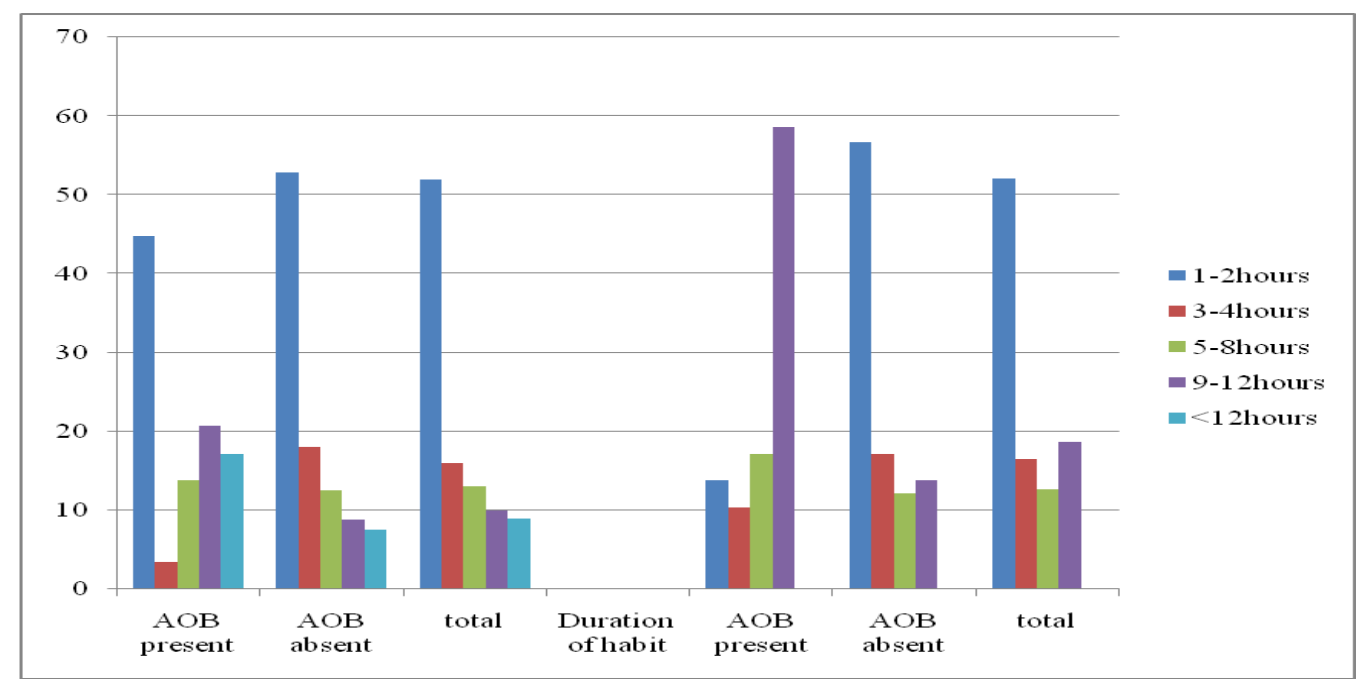

Figure 1: Relationship between AOB and frequency and duration of habits

\section{Discussion}

The prevalence of anterior open bite in 2 to 5 -yearold children in this study is $2.8 \%$ which is similar to another study carried out in pre-school children of $2-4 \%{ }^{10}$ but lower than $8 \%{ }^{13}$ and $7.9 \%{ }^{14}$. However, prevalence rates of $1.6 \%{ }^{19}, 4.1$ to $4.4 \%{ }^{2}, 21,5.5$ to $16.5 \%{ }^{13-16,30}$ have been reported in other studies in older children. Racial differences were observed for anterior open bite in children with values ranging from $4-8 \%$ in white Americans ${ }^{1,31}, 7-16 \%$ in African Americans ${ }^{15,31}, 10-16.5 \%$ in East Africans ${ }^{16,17}$ and $2-4 \%$ in British subjects ${ }^{10}$. The prevalence of $2.8 \%$ in this study is however consistent with the results from the study by Burford and Noar ${ }^{10}$. This could be because the same age group was studied.
There was no statistically significant difference between the frequency and duration of the various sucking habits, $\mathrm{p}>0.05$. Those children who sucked for 1-2 hours and 0-5 months exhibited the highest frequency with $55(73 \%)$. 
with the results of other studies ${ }^{2-4,6-20}$ were the thumb and finger also exhibited the highest frequency and were most implicated in the formation of an anterior open bite. This is also in agreement with studies by Onyeaso and Sote ${ }^{20}$ on oral habits where thumb and digit sucking were implicated in the aetiology of anterior open bites. This study found a significant relationship between oral habits and anterior open bite and that thumb sucking was the most important aetiologic factor with a prevalence of $33 \%$ which is close to the findings of Larsson ${ }^{30}$ who reported prevalence of $30 \%$ but far from the findings of Onyeaso and Sote ${ }^{20}$ who reported a prevalence of $10.7 \%$. Their study ${ }^{20}$ reported a significant relationship between finger sucking and anterior open bite.

This study showed that there was a statistically significantly higher prevalence of asymmetric anterior open bite in children with sucking habits than those without. Thumb suckers in this study showed the highest prevalence of asymmetric open bite in $7.5 \%$. Studies by Ngan and Fields ${ }^{9}$, Burford and Noar ${ }^{10}$ and Isiekwe ${ }^{12}$, reported an asymmetric open bite with the thumb sucking habit.

Other oral habits like the tongue ${ }^{1-3,24-26}$, pacifier ${ }^{1,30-32,}$ and lip and cheek sucking ${ }^{2,10}$ have been implicated in the aetiology of an anterior open bite. This is consistent with the findings from this study where the tongue, lip and cheek were found to have implicated in the formation of an anterior open bite. Other studies reported a prevalence of $1.6 \%{ }^{22}$ with the tongue thrusting habit which is far lower than the prevalence of $17.2 \%$ reported for this study. Tongue habits vary from retained infantile swallow, tongue thrusting, sucking, and variations in size and posture $^{1-3,4}$ and this could explain the variation in prevalence rates in the two studies. The use of the pacifier is not common in this environment therefore; there was no formation of an open bite with the use of the pacifier in this study. Pacifier sucking ${ }^{31}$ has been reported to have a high prevalence rate of $38-94 \%{ }^{31}, 76 \%{ }^{24}$ and $95 \%{ }^{30}$ in other countries, but in this study a low prevalence of $4.5 \%$ was reported. This compares favorably with another Nigerian study ${ }^{22}$ where the pacifier was not used by any of the children studied. The pacifier suckers in this study however exhibited no open bite. This could be as a result of the small number of children in this study that used the pacifier as compared to other studies $10,24,30-32$ with a larger number using the pacifier. This may also be attributed to cultural and ethnic differences in the various studies.

This study found a statistically significant difference in the number of 4-year old children with anterior open bite. This is similar with the results of the study by Ravn ${ }^{24}$ who demonstrated that anterior open bite is more common in 3-year-old children who persist in a sucking habit. Fukuta et al ${ }^{27}$ also found out that there appeared to be an increased tendency to anterior open bite and malocclusion in children who persisted in the thumb and digit sucking habit after 4 years of age.

This study reported the presence of an anterior open bite with an increased frequency and duration of a thumb and digit sucking habit. Children who sucked between 1-3 hours a day and for 24-60 months exhibited the highest frequency of anterior open bite with $44.8 \%$ and $58.6 \%$ respectively. This study however showed no significant difference between the frequency of the various habits and anterior open bite. There was also no statistically significant difference the frequency and duration of the various sucking habits, and this compares favorably with studies by Adair et $\mathrm{al}^{32}$ where there was also no difference between the frequency and duration of the various sucking habits.

\section{Conclusion}

The prevalence of $\mathrm{AOB}$ is this study appears to be similar to that in British children however; other races appear to have a higher prevalence rate than those reported from the above study.

This study revealed that the most important aetiological factors are thumb finger and tongue thrusting but thumb sucking has been identified as the most important aetiological factor in the formation of an anterior open bite in pre-school children.

\section{References}

1. Ng CST , RWK Wong, Hagg U . Orthodontic treatment of anterior open bite. Int J Paed Dent 2008; 18: 78-83.

2. Subtelny J.D Sakuda M. Open bite. Am J Orthod 1964; 60: 337-58

3. McSherry P.F. Aetiology and treatment of anterior open bite. J Irish Dent Assoc 1996; 42: 20-6

4. Mizrahi E. A review of anterior open bite. Br J Orthod 1978; 5: 21-6. 
5. Hak JK, Bevis RR, Waite DE. Apertognathia (open bite) and its surgical management. Int J Oral Surg 1984; 13:278-9.

6. Richardson A. A classification of open bites. Eur J Orthod 1981; 3:288-96.

7. Otuyemi OD, Noar JH. Anterior open bite: A review. Saudi Dent J 1997; 9 : 149-57.

8. Gershater MM. The proper perspective of open bite. Angle Orthod 1972; 42 : 263-72.

9. Ngan P, Fields HW. Open bite: review of aetiology and management. Paediatr Dent 1997; 19: 91-8

10. Burford D, Noar JH. The causes, diagnosis and treatment of anterior open bite. Dent update 2003; 30: 235-41.

11. Popovich F, Thompson GW. Thumb and finger sucking: its relation to malocclusion. Am J Orthod 1973; 63:148-55.

12. Isiekwe MC. Malocclusion in a Lagos community. Dent Oral Epidemiol 1983; 11:59-62.

13. Jones ML, Mourino AP, Bowden TA. Evaluation of occlusion, trauma, and dental anomalies in African-American children of metropolitan headstart programs. J Clin Pediatr Dent 1993; 18: 51-4.

14. Carvalho AC, Paiva SM, Scarpelli AC, Viegas CM, Ferreira FM, Pordeus IA. Prevalence of malocclusion in primary dentition in a population-based sample of Brazilian preschool children. Eur J Paediatr Dent 2011; 12:107-11.

15. Harila V, Heikkinen T, Gron M, Alvesalo L. Open bite in prematurely born children. J Dent Child (Chic) 2007; 74: 165-70.

16. Hassanali J, Pokhariyal GP. Anterior tooth relations in Kenyan Africans. Arch Oral Biol 1993; 38: 337-42.

17. Kerosuo H. Occlusion in the primary and early mixed dentitions in a group of Tazanian and finnish children. ASDC J Dent Child 1990; 57: 293-98.

18. Motegi E, Miyazaki H, Ogura I, Konishi H, Sebata M. An orthodontic study of Temporomandibular joint disorders. Angle Orthod 1992; 62: 249-55.

19. Borzabadi-Earahani A, Borzabadi-Earahani A, Eslamipor F. Malocclusion and occlusal traits in an urban Iranian population. An epidemiological study of 11 to 14-year-old children. EurJ Orthod 2009; 31: 477-84.

20. Onyeaso CO, Sote EO. Prevalence of oral habits in 563 Nigerian preschool children aged 3-5 years. Niger Postgrad Med J 2001; 8: 193-5.

African Health Sciences Vol 12 Issue 4 December 2012
21. Ajayi EO. Prevalence of malocclusion among school children in Benin City, Nigeria. JMBR 2008; 7: 58-65.

22. Onyeaso CO, Sote EO, Arowojolu MO. Need for preventive and interceptive orthodontic treatment in 3-5 year old Nigerian children. Afr J Med Med Sc 2002; 2: 115-18.

23. Maciel CT, Leite IC. Etiological aspects of anterior open bite and its implications to the oral functions. Pro-Fono Revista de Atualizacao Cientifica 2005; 17: 293-302.

24. Ravn JJ. Sucking habits and occlusion in 3-yearold children. Scand J Res 1976; 84 :204-9

25. Farsi N M, Salaman F S. Sucking habits in Saudi children: prevalence, contributing factors and effects on the primary teeth. Paediatr Dent 1997; $19: 28-33$.

26. Duncan K, McNamara C, Ireland AJ, Sandy JR. Sucking habits in childhood and the effects on the primary dentition: Findings of the Avon longitudinal study of pregnancy and childhood. Int J Paediatr Dent 2008; 18: 178-88.

27. Fukuta O, Braham R.L, Yokoi K, Kurosu K. Damage to the primary dentition resulting from thumb and finger (digit) sucking. ASDC J Dent Child 1996; 3: 403-7

28. daCosta OO, Orenuga OO. Dentofacial anomalies related to the digit sucking habit. Afr J Med Med Sc 2002; 31: 239-42.

29. Sofoluwe GO et al. Principles and practice of public health in Africa 1996; $\left(2^{\text {nd }}\right.$ ed) University Press PLC, vol1; 114-15.

30. Larsson E. The prevalence and aetiology of prolonged dummy or finger sucking habits. Eur J Orthod 1985; 7:172-6

31. Kelly JE, Sanchez M, van Kirk LE. An assessment of the occlusion of teeth in children. US Public Health Service DHEW Pub No (HRA) 1971; 74-1612, Washington DC National Center for health statistic.

32. Adair S.M, Milano M, Dushku J.C. Evaluation of the effects of orthodontic pacifiers on the primary dentition of 24-59 month old children: Preliminary study. Paediatr Dent 1992; 14: 13-18

33. Ogaard B. Dummy and finger sucking habits among 5-year-old children. An investigation of frequency and effect on the dentition and occlusion. Nor Tannlaegeforen Tid 1989; 99: 20612. 